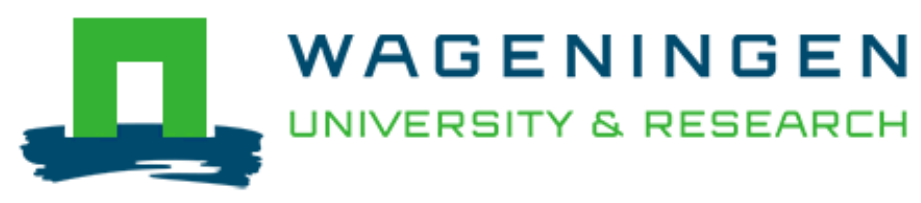

\author{
Ecology of Plastic Flowers \\ Rusman, Q., Lucas-Barbosa, D., Poelman, E. H., \& Dicke, M.
}

This is a "Post-Print" accepted manuscript, which has been Published in "Trends in Plant Science"

This version is distributed under a non-commercial no derivatives Creative Commons (c) (1) $\$($

(CC-BY-NC-ND) user license, which permits use, distribution, and reproduction in any medium, provided the original work is properly cited and not used for commercial purposes. Further, the restriction applies that if you remix, transform, or build upon the material, you may not distribute the modified material.

Please cite this publication as follows:

Rusman, Q., Lucas-Barbosa, D., Poelman, E. H., \& Dicke, M. (2019). Ecology of Plastic Flowers. Trends in Plant Science, 24(6), 725-740.

https://doi.org/10.1016/j.tplants.2019.04.007

You can download the published version at:

https://doi.org/10.1016/j.tplants.2019.04.007 


\section{Ecology of plastic flowers}

Quint Rusman ${ }^{1}$, Dani Lucas-Barbosa ${ }^{1,2}$, Erik H. Poelman ${ }^{1}$, Marcel Dicke ${ }^{1}$

${ }^{1}$ Laboratory of Entomology, Wageningen University, P.O. Box 16, 6700 AA Wageningen, The Netherlands

${ }^{2}$ Current address: Bio-communication \& Ecology, ETH Zürich, Schmelzbergstrasse 9, 8092

Zürich, Switzerland

Correspondence: quint.rusman@wur.nl (Q Rusman).

Keywords: flower visitors, flower traits, herbivore-induced plant responses, plant defence, phenotypic plasticity, specificity

\section{Abstract:}

Plant phenotypic plasticity in response to herbivore attack includes changes in flower traits. Such herbivore-induced changes in flower traits have consequences for interactions with flower visitors. Here, we synthesize current knowledge on the specificity of herbivore-induced changes in flower traits, the underlying molecular mechanisms and the ecological consequences for flower-associated communities. Herbivore-induced changes in flower traits seem to be to a large extent herbivore-species-specific. The extensive plasticity observed in flowers influences a highly connected web of interactions within the flower-associated community. We argue that the adaptive value of herbivore-induced plant responses and flower plasticity can only be fully understood from a community perspective, rather than from pairwise interactions.

\section{Flowers and their environment}

The angiosperms, which comprise the majority of plant species, are characterized by an incredible diversity in flowers that range from the tiny millimetre-long flowers of duckweed (Lemna minor) to the giant meter-wide corpse flower (Rafflesia arnoldi) [1, 2]. The diversity of 
shapes, colours and scents of flowers is largely a result of evolution with an even more diverse flower-associated community $[3,4]$. This community includes mutualists, such as pollinators (see Glossary), predators and parasitoids, as well as antagonists, such as herbivores and pathogens [5-7]. As flowers are the reproductive organs of the plant, their displays are under selection to maximize reproduction under varying environmental conditions. Flowering plants are therefore expected to respond to the environment, including visitation by antagonists and mutualists. Indeed, flower traits readily change in response to herbivory or pathogen attack, even when these antagonists attack plant organs other than flowers [8, 9]. Flower traits also change in response to the activity of mutualists such as pollinators [10-13] and beneficial microbes [14-16]. Here, we focus on herbivore-induced changes in flower traits, because despite accumulating data on this topic, we still have important knowledge gaps. It is unclear if there are general patterns in flower phenotypic plasticity to different types of herbivores, and whether such plasticity is adaptive for the plant. Alternatively, herbivore-induced changes that are non-adaptive may merely change as pleiotropic effects of herbivore-induced plant responses via resource trade-offs, genetic, biochemical or functional linkage (see Box 1). Because changes in flower traits mediate interactions with multiple flower-associated community members, we need to adopt a community approach to understand flower trait plasticity $[6,7,17,18]$. In this review, we discuss 1$)$ the current knowledge on the specificity of induction and to what extent herbivore-induced changes affect flower traits, 2) what are the underlying molecular mechanisms of flower plasticity, 3) the adaptive value of herbivoreinduced flower plasticity in mediating interactions with flower visitors, and 4) the ecological consequences of floral plasticity for flower-associated communities.

\section{Specificity of herbivore-induced floral plasticity}

The influence of herbivore-induced changes on flower traits and consequences for flower visitors was first recognized more than two decades ago [19] (Figure 1, Key Figure). Since then, it has become apparent that floral plasticity in response to herbivory differs among plant species, and ranges from limited to extensive plasticity $[17,20,21]$ (Table 1). For example, folivory by Trichoplusia ni affects flower morphology of Campanula rotundifolia, floral volatile blend composition of Heterotheca villosa, whereas it does not affect flower traits of Phacelia hastata or Potentilla recta [21]. In Brassica nigra, a range of herbivore species that commonly attack this species change multiple traits simultaneously, including floral morphology, 
volatiles, colour, nectar and pollen production [8]. Some flower traits are more plastic than others, either because their expression is more plastic $[22,23]$, or because they are more closely connected to physiological regulation of plant defences (Box 1). Especially flower phenology, morphology, and volatile emission seem to be plastic in response to herbivory, while nectar production changes in some cases, but not in others (Table 1). Few studies investigated a set of multiple flower traits, e.g. flower colour, pollen production and chemistry are rarely investigated. When measured, colour and pollen production show changes in response to herbivory, but not necessarily so $[8,12,24,25]$. For instance, the reflectance spectrum of flowers might not change in response to herbivory $[20,24]$, or change by reflecting higher or lower intensities of specific wavelengths like yellow and UV [8]. When pollen production changes in response to herbivory, this is mostly by a reduction in the amount of pollen produced $[8,25]$.

Besides variation in plant species and traits, herbivore-induced changes in flower traits vary with herbivore identity and feeding behaviour (Table 1). Because herbivore-induced plant responses often contain a systemic component, and defence and reproduction are physiologically linked (Box 1), we expect similar patterns of specificity in the induction of flower traits as for defence traits. Specificity of induction of foliar defence traits often includes a general component based on the feeding mode and feeding site of the herbivore and a more specific component based, among others, on herbivore identity [26-29]. The limited direct evidence we have suggests that changes in flower traits are to a large extent herbivore-species specific (Table 1). Indirect evidence gained by comparing different studies supports this. For example, the application of jasmonic acid (JA) on leaves of Brassica nigra, which induces the general component of herbivore-induced plant responses against chewing herbivores, reduced nectar production in the flowers, whereas folivory by Pieris rapae or $P$. brassicae caterpillars, two chewing herbivores that induce JA, increased nectar production or had no effect $[30,31]$. To explain differences in specificity of induction between foliar and floral tissues, we need to consider the underlying physiological mechanisms.

\section{Physiological regulation of flower plasticity}

Herbivore-induced changes in plant leaves are well known to be mediated by phytohormonal signal-transduction pathways [32]. Emerging evidence indicates that flowers, just as leaves, respond to herbivory by activating phytohormonal signalling. Increased expression of the JA 
biosynthesis gene LIPOXYGENASE-2 (LOX2) can be induced in various floral tissues by exogenous methyl jasmonate [33], and leaf herbivory can induce the expression of JA biosynthesis genes, such as ALLENE OXIDE SYNTHASE (AOS) in the flowers [34, 35], with subsequent induction of JA [34, 36, 37]. In contrast to leaves, concentrations of floral salicylic acid (SA) have so far not been shown to change in response to herbivory, while for abscisic acid (ABA) evidence suggests that herbivory has either no effect or results in increased concentrations of ABA in flowers $[34,36]$. Despite the apparently conserved phytohormonal signalling in leaves and flowers (Box 2), important tissue-specific patterns in the accumulation and regulation of signalling pathway components have been identified [38]. This may explain the discrepancy in specificity of herbivore induction between foliar and floral tissues. So far, the accumulation and regulation of foliar and floral tissue-specific components have mostly been documented for the JA-pathway. The constitutive accumulation of ALLENE OXIDE CYCLASE (AOC) mRNA and proteins was found to be higher in tomato flowers compared to leaves, and also differed between flower tissues [39]. The accumulation of AOC mRNA and proteins was accompanied by tissue-specific increases in the concentrations of JA, 12-oxophytodienoic acid (OPDA), and jasmonoyl-L-isoleucine (JA-Ile). When AOC was overexpressed in tomato, this increased JA and OPDA concentrations in buds and flowers, but not in leaves [40]. The increase in JA and OPDA concentrations differed among floral tissues, resulting in specific ratios of these compounds in various flower organs. Biosynthesis of JA in the stamens of $A$. thaliana starts with the expression of DEFECTIVE IN ANTHER DEHISCENCE1, which is not expressed in other flower tissues [41]. In pea (Pisum sativum), a LOX gene has been identified which is predominantly expressed in the flowers, and shows differential expression in flower tissues, with the highest expression in petals and carpels [42]. Together, these results suggest differential regulation of JA biosynthesis between leaves and flowers, and even different flower organs, via the tissue-specific accumulation of conserved pathway components and the presence of unique pathway components. Such tissue specificity is also present in the JAinduced part of the signalling pathway. Specific types of JASMONATE ZIM-DOMAIN (JAZ) and MYB proteins are found in flowers, that are not expressed in leaves [43-46]. These specific JAZ proteins are important for the accumulation of constitutive defences [43]. Moreover, JAZ proteins that occur both in leaves and flowers can serve different functions, with different regulatory targets [47]. Especially JAZ proteins and transcription factors (TFs) such as MYCs, MYBs and APs, may be important for tissue-specific regulation of particular processes, such as 
flower development and defence [46, 48-50]. For example, in Arabidopsis flowers JAZ1, 3, 4 and 9 proteins interact with the TFS TOE1 and TOE2 to regulate CORONATINE INSENSITIVE 1 (COI1)-dependent flowering, but not COI1-dependent defence gene expression [48]. Also, MYB and WRKY TFs, and multiple CYP94-genes - important in feedback mechanisms of JA-Ile - are differentially expressed in leaves and flowers, and even in different floral tissues $[45,51$, 52].

Regarding the SA-pathway, leaves and flowers can contain different concentrations of free and total SA, which results in tissue-specific transcriptional responses of SA-regulated defence genes [36, 53]. Moreover, SA concentrations and gene transcription levels also differ between sepals and petals, although the differences are smaller compared to leaves. The TF HAHB10 is induced in sunflower leaves after SA treatment and pathogen attack, but repressed after wounding [54]. This TF increases the expression of multiple genes involved in flowering, and represses the expression of multiple genes involved in JA- and SA-mediated defence. Interestingly, this TF is mostly expressed in mature leaves, and almost absent in floral tissues, except for the carpels [54].

This suggests that regulation of development and defence is different in vegetative and floral tissues of flowering plants. Tissue-specific gene expression patterns and regulatory components likely lead to different plant responses in leaves versus flowers. Indeed, floral and foliar herbivory induce different changes in the plant $[35,55]$, and plant responses to foliar herbivory differ for foliar and floral tissues [12, 30, 37]. Flowers even respond differently to attack on different systemic tissues. For example, root and foliar herbivory induce different changes in flower traits $[8,56]$ (Figure 1). Moreover, the plant as an integrated phenotype can adopt different defence strategies depending on plant ontogeny [57], and specifically between vegetative and flowering stages $[58,59]$. The timing of herbivory over plant ontogeny can therefore result in different patterns of herbivore-induced plant responses [60]. Taken together, tissue-specific and ontogeny-specific expression of genes and regulatory components with resultant differential expression of plant responses likely explain the differences in specificity of herbivore-induced changes in plant traits between leaves and flowers. Such knowledge on the underlying mechanisms allow us to manipulate the plant phenotype, while preserving the context of these complex interactions, to test effects of floral plasticity on other organisms present in the environment, and plant fitness. 
Flower traits that commonly change in response to herbivory are hypothesised to be adaptive by mediating interactions that maximize reproductive output, thus benefiting plant fitness (Figure 2). By now, we acknowledge that floral volatiles commonly change in response to herbivory and that these are exploited by natural enemies of herbivores [24,61, 62]. Although plant fitness benefits through the attraction of natural enemies of herbivores are intuitive and have been shown for plants in interactions with herbivores and natural enemies in the vegetative stage [63], these remain largely elusive for flowering plants (but see [64]). Herbivore-induced changes can increase the attraction of pollinators $[8,65,66]$, potentially via changes in floral volatile emission [67]. An increased attraction of pollinators can increase reproductive output $[67,68]$, but not necessarily [65], and this likely depends on conditions such as pollen and resource limitations. Herbivore-induced changes can lead to increased resistance to florivores, seed predators, and nectar thieves $[66,69]$, by changes in flower chemistry $[7,37,70,71]$. Leaf-herbivore-induced resistance to seed predators benefits plants of Oenothera biennis by reducing seed predation to a large extent, whereas leaf herbivory itself had little impact on reproductive output [37]. Hence, herbivore-induced changes in flower traits that mediate interactions with mutualistic or antagonistic flower visitors may be adaptive for the plant.

In contrast to benefits, changes in flower traits may result in ecological costs $[55,72]$. The most commonly reported ecological cost is a reduction in pollinator visitation [17, 55], mediated by herbivore-induced changes in floral volatiles, morphology, colour, and/or rewards (Figure 2) [8, 24, 55, 73]. Such reductions in pollinator visitation can negatively affect plant reproductive output [73], but not necessarily, again depending on conditions such as pollen and resource limitations [74, 75]. Herbivore-induced flower traits may also interfere with the optimization of pollination. For example, plants use honest signalling to increase flower constancy and pollination effectiveness [76]. With honest signalling, plants provide one or a few cues, such as volatile compounds or flower size, that are reliable indicators of flower rewards. By altering flower volatile emission, morphology, size, and nectar and pollen production, herbivores potentially interfere with honest signalling [8, 77]. Herbivory can also alter local changes in flower traits in response to visitation by flower visitors. Pollination often induces changes in flower volatile emission, colour and morphology, resulting in reduced 
visitation by other pollinators to already pollinated flowers [10-13]. Pollination-induced changes in, for example, floral volatiles can be dependent on whether the plant is simultaneously attacked by herbivores [12], which might reduce pollination effectiveness. Interestingly, ecological costs of changes in flower phenotype in terms of reduced pollination can be compensated for by simultaneous changes in plant mating system [78], by, for example, increasing autogamous selfing [79]. Herbivore-induced changes can increase the attraction of florivores by changing apparency traits such as plant height, or flower colour and volatile emission [69], with potential negative effects on plant reproduction [80]. Thus, herbivore-induced changes in flower traits can be detrimental for plant reproduction by altering interactions with flower visitors.

Herbivore-induced changes in interactions with flower visitors seem adaptive in some cases, such as increased resistance to florivores, while maladaptive in others, such as the reduced visitation by pollinators (Figure 2). Despite these insights, we lack studies that specifically target fitness effects of plant responses to herbivory [81], and link these to altered interactions with flower visitors. To understand the adaptive value of flower plasticity with contrasting effects on pairwise interactions, it is important to adopt a community perspective.

\section{Consequences for flower-associated communities}

The flower-associated community is highly diverse and includes mutualists such as pollinators, predators, parasitoids, and beneficial microorganisms as well as antagonists such as herbivores and pathogenic microorganisms [5-7]. Flowers are visited by one or multiple pollinator species, predominantly bees, flies, butterflies and moths, or beetles. The composition of the pollinator community might be very specific for plant species, even when those plants are part of the same plant community. Generalist predators such as crab spiders, true bugs, and social wasps use flowers as hunting grounds [64, 82], whereas specialist parasitoids may visit flowers to find their specific hosts $[6,24,62]$. Herbivores visit flowers frequently, and as larvae or adults can consume specific organs or the complete flower [7]. Florivores can feed exclusively on flowers, but also start feeding on leaves and move to the flowers later in development, or switch diet when flowers become available [83]. In addition to interactions with insects, flowers contain a rich microbial community consisting of fungi, bacteria, archaea, and viruses [84]. These microbes can be antagonists by destroying flower 
tissues, opportunists that exploit the transient habitat without benefits or detriments to the flowers, or mutualists by competing for niche space with antagonistic microbes. The floral microbial community shows considerable variation in space, various flower organs, and time [84]. Some flower visitors use flower traits for host-plant location, whereas the growth and survival of most of these organisms is affected by the chemical composition of the flowers [7, $84,85]$. Therefore, we expect herbivore-induced changes in flower traits to have major impact on flower-associated community dynamics.

Herbivore-induced changes in flower traits have flower-community wide consequences. Pollinator community composition can be different for herbivore-infested plants compared to uninfested plants $[20,68,86]$, but not necessarily $[21,83]$, and this may depend on the identity and feeding guild or feeding site of the herbivore [68]. Florivore community assembly can be affected by early-season leaf herbivory [87]. Interestingly, the florivore community of Brassica oleracea was affected differentially by the sequence of arrival of two leaf-feeding herbivores early in the season [87]. Although there is no direct evidence that herbivore-induced changes in flower traits affect floral microbial community composition, this is most likely [88]. Herbivore-induced changes in flower traits include many characteristics that affect the abundance and diversity of floral microbes such as nectar composition and volatile emission [84]. Chemical properties of nectar are a prime determinant of microbial communities in nectaries. For example, the composition of secondary metabolites such as pyridine-type alkaloids affect bacterial community richness, diversity and composition in the nectar [89], and herbivory can increase nectar alkaloid levels [90]. Therefore, we expect that changes in flower traits in response to herbivory affect floral microbial communities.

Flower plasticity can link multiple interactions between flower visitors. Flowers are generally short-lived [91]. Flower-associated organisms all interact with flowers during this short time window. Flower visitors that respond to herbivore-induced changes in flower traits, so-called receivers, can become inducers themselves when their activities induce additional changes in flower traits (Figure 3). Such flower-visitor-induced changes in flower traits can subsequently affect other flower visitors [12-16, 66], and even feedback to leaf herbivores [69]. Changes in flower phenotype in response to each interacting flower visitor will result in multiple linked indirect interaction units, where one interaction unit comprises an inducer, the mediator (the flower(s)), and a receiver (Figure 3) [92]. For example, herbivory can induce changes in nectar 
composition and volatile emission [30, 90], which subsequently affect nectar microbial community composition and pollinator visitation [12, 30, 68, 89]. Different nectar microbial communities may induce further changes in nectar composition and volatiles, which affect parasitoid foraging and performance [14, 16], and pollinator visitation [15]. Indeed, artificial florivory, pollination, and nectar robbery have been shown to affect multiple subsequent flower visitors at the same time, including pollinators, nectar thieves and robbers, florivores, and predators $[66,69]$. Interestingly, most effects were non-additive which suggests that the effect of one flower visitor can depend on the presence or behaviour of other flower visitors. Taken together, the extensive plasticity of flowers likely results in a highly connected web of interactions within the complete flower-associated community.

Although flower plasticity most likely has community-wide effects, broader patterns are difficult to predict. We still lack detailed knowledge on flower plasticity in response to the community; e.g. how flowers respond to sequential induction by different interactors or multiple interactors at the same time. Different interactors may vary in the magnitude of induced changes in flowers, with supposedly varying community-wide effects. Leaf and root herbivory induce systemic changes in the plant, likely affecting all flowers in the inflorescences, with high potential to affect temporal or spatially displaced flower visitors [68, 73]. For floral herbivory, herbivore-induced changes can be local, which would restrict the effects to visitors of that specific flower or a specific inflorescence. For example changes in flower phenotype due to feeding damage by florivores can be restricted to individual flowers, and damaged flowers subsequently receive fewer pollinator visits [93, 94]. Moreover, the tissue/organ that is damaged can influence how the flower appears to flower visitors $[95,96]$. For example, nectar-guide removal in Alstroemeria ligtu reduced pollinator visitation, whereas lateral red tepal removal did not [96]. Interestingly, damaged flowers can also reduce visitation to undamaged flowers in the inflorescence [97], either due to systemic changes in the whole inflorescence, or because pollinators judge potential food plants on the plant level and therefore avoid damaged plants as a whole. Pollinator- and microbe-induced changes in flower traits are expected to be mostly local. Some of these local effects, such as pollinatorinduced changes in flower longevity, affect plant appearance as a whole, and thereby pollinator and florivore visitation to non-induced flowers $[13,98]$. Thus, community-wide 
effects of flower plasticity likely vary considerably depending on the type of inducer, and whether induction is local or systemic.

It is also worth considering how such effects will vary depending on plant phenological traits such as flower longevity and abundance. Plant species can differ greatly in flower longevity and abundance, from having just a few flowers that can last multiple months, to having hundreds of flowers that last for a few days or less [91]. Community-wide effects of local induction are probably much more extensive for plant species with a few long-lived flowers compared to plant species with a high floral turn-over. The extent of floral plasticity can also vary depending on flower longevity and abundance. Long-lived flowers are expected to be more plastic to continuously adapt to environmental variation $[13,91]$. Orchids with their relatively long-lived flowers, for example, alter flower longevity depending on variation in the biotic environment, i.e. the presence of pollinators which pollinate the flower [91]. Although potentially less affected by local pollinator-induced changes, short-lived flowers still readily change in response to systemic induction by herbivores [56]. Local microbe-induced changes might affect short- and long-lived flowers to the same extent, because microbes directly modulate flower traits rather than indirectly via changes in plant physiology [84, 99]. The consequences of such microbe-induced changes will be more apparent for plants with longlived flowers, however, due to the lower rate of flower turn-over and smaller numbers of flowers [91]. Hence, flower longevity and abundance can be important for community-wide effects of local and systemic induction.

Lastly, responses of certain groups of flower visitors to flower plasticity are better understood than others, and we specifically lack fundamental knowledge on if and how herbivore-induced changes affect floral microbial community composition, differential responses of microbe species, and differential effects on microbes inhabiting different floral organs. Although it seems likely that flower plasticity has community-wide effects, we still have important gaps in our knowledge with respect to flower plasticity, to what extent such plasticity may be explained by plant life-history traits, and what the consequences for flower visitors are.

\section{Concluding remarks and future perspectives}

To understand the ecology of flower plasticity, we need to adopt a community context approach. The evolution of flowers cannot be fully explained by focussing solely on pollinators, but rather by combined selection of the flower-associated community, e.g. pollinators, 
florivores, and microbes $[3,66]$. Likewise, the evolution of plant defences cannot be fully explained by focussing solely on herbivores, and theories on plant defence evolution will benefit from including plant reproduction. For example, outcrossing Nicotiana species have lower nicotine concentrations in leaves, flowers, and nectar compared with selfing species [100]. Defensive traits may evolve from pre-existing traits with reproductive functions, and hence reproductive evolutionary history may help to explain the current defence phenotype [101]. Moreover, communities are characterized by ample indirect interactions among their members. These indirect interactions are as important as direct interactions are in shaping evolution [72, 102-104]. Hence, organisms such as herbivores not directly associated with the flowers can contribute to flower evolution by indirectly affecting interactions with flower visitors (non-additive selection). The herbivore-species-specific nature of flower plasticity in response to herbivory suggests a high number of potential selective agents, but also large temporal and spatial fluctuations in selection pressure exhibited by such indirect interactions. Particular plant traits such as flower longevity and abundance, or the ability to separate foliar from floral plant responses, or defence and reproduction for the plant as a whole, may determine the extent of non-additive selection by indirect interactions. Separation of foliar from floral plant responses, and defence and reproduction, can partly be achieved by tissuespecific gene expression and regulatory components, and plant ontogenetic trajectories in growth-defence-reproduction strategies. Still, it might be difficult for plants to completely separate processes in leaves and flowers, and defence and reproduction, due to various physiological links that allow plants to function as one integrated entity. Exploring the ecology of plastic flowers will extend our understanding of the evolution of plant defence and reproduction.

To better understand flower plasticity in response to herbivory, we need to deepen our knowledge on specificity of induction, for example by using combinations of herbivores that show patterns of induction of changes in foliar and/or root traits related to feeding guild, feeding site, or host plant specialization. Such studies should measure a multitude of flower traits because specificity of induction can only be judged when considering the complete flower phenotype. We have just started to unravel the molecular mechanisms underlying specificity in flower plasticity, especially how phytohormones, secondary metabolites, and defence genes are expressed in the flowers $[43,47,48,51,53]$. More insight into such tissue- 
specific plant responses will shed light on which of the potential links between defence and reproduction (Box 1) are common and important in flower plasticity in response to herbivory. Moreover, research on specificity of induction will provide broader insights in how flowering plants deal with ecological variation, and optimize the attraction of mutualists while dealing with antagonists. The consequences of floral plasticity should be investigated in a community context, and should consider adaptive plasticity, with consequences for plant reproduction. An interesting approach would be to focus on keystone herbivores: herbivores that have a large effect on the interaction network with associated fitness consequences for the plant [72]. Keystone herbivores that especially affect the flower-visitor community can be compared with keystone herbivores that have large effects on foliar and/or root communities, and nonkeystone herbivores to identify how such herbivores drive selection in complex communities, and what the contribution of flower plasticity and the flower-associated community is. Another interesting approach will be to compare responses of flower-associated communities varying in their overall degree of host plant specialization [17], because these might differentially impact plant fitness, and open up different evolutionary trajectories. In addition to systemic induction, the role of local flower plasticity in response to herbivory, but also pollination and microbial induction, needs further attention (See Outstanding Questions). The community-wide effects of local compared to systemic flower plasticity have so far not been explored, and it will be interesting to compare flower plasticity of plants with particular traits, such as flower longevity and abundance, in this perspective. Comparing plants with particular defensive flower traits, and applying explicit hypothesis from theories on the evolution of plant defence will reveal if we can generalize patterns of defences in flowering plants as we have done for plants in the vegetative stage [105]. For example, do plants with apparent flowers invest more in constitutive defences in the flowers whereas plants with unapparent flowers invest more in inducible defences in the flowers? Answers to such questions will facilitate the integration of evolutionary theories on plant defence and reproduction and help explain flower plasticity in response to herbivory (see also outstanding questions).

\section{Acknowledgements}

This work was supported by the Earth and Life Science council of the Netherlands Organisation for Scientific Research (NWO-ALW) (grant nr. 831.14.004). 
References

1. Soltis, P.S. and Soltis, D.E. (2014) Flower diversity and angiosperm diversification. In Flower Development: Methods and Protocols (Riechmann, J.L. and Wellmer, F. eds), pp. 85102, Springer New York.

2. Moyroud, E. and Glover, B.J. (2017) The evolution of diverse floral morphologies. Curr Biol 27, R941-R951.

3. Strauss, S.Y. and Whittall, J.B. (2006) Non-pollinator agents of selection on floral traits. In Ecology and evolution of flowers (Harder, L.D. and Barrett, S.C.H. eds), pp. 120-138, Oxford Univ. Press.

4. Schiestl, F.P. and Johnson, S.D. (2013) Pollinator-mediated evolution of floral signals. Trends Ecol Evol 28, 307-315.

5. Junker, R.R. and Keller, A. (2015) Microhabitat heterogeneity across leaves and flower organs promotes bacterial diversity. FEMS Microbiol Ecol 91, fiv097.

6. Lucas-Barbosa, D. et al. (2011) The effects of herbivore-induced plant volatiles on interactions between plants and flower-visiting insects. Phytochemistry 72, 1647-1654.

7. McCall, A.C. and Irwin, R.E. (2006) Florivory: the intersection of pollination and herbivory. Ecol Lett 9, 1351-1365.

8. Rusman, Q. et al. (2019) Floral plasticity: Herbivore-species-specific-induced changes in flower traits with contrasting effects on pollinator visitation. Plant, Cell Environ, In press.

9. McArt, S.H. et al. (2014) Arranging the bouquet of disease: floral traits and the transmission of plant and animal pathogens. Ecol Lett 17, 624-636.

10. Rodriguez-Saona, C. et al. (2011) Variation in highbush blueberry floral volatile profiles as a function of pollination status, cultivar, time of day and flower part: implications for flower visitation by bees. Ann Bot 107, 1377-1390. 
11. Willmer, P. et al. (2009) Bidirectional flower color and shape changes allow a second opportunity for pollination. Curr Biol 19, 919-923.

12. Lucas-Barbosa, D. et al. (2016) Visual and odour cues: plant responses to pollination and herbivory affect the behaviour of flower visitors. Funct Ecol 30, 431-441.

13. van Doorn, W.G. (1997) Effects of pollination on floral attraction and longevity. J Exp Bot 48, 1615-1622.

14. Lenaerts, M. et al. (2017) Nectar bacteria affect life history of a generalist aphid parasitoid by altering nectar chemistry. Funct Ecol 31, 2061-2069.

15. Rering, C.C. et al. (2018) Nectar-inhabiting microorganisms influence nectar volatile composition and attractiveness to a generalist pollinator. New Phytol 220, 750-759.

16. Sobhy, I.S. et al. (2018) Sweet scents: Nectar specialist yeasts enhance nectar attraction of a generalist aphid parasitoid without affecting survival. Front Plant Sci 9, 1009.

17. Lucas-Barbosa, D. (2016) Integrating studies on plant-pollinator and plant-herbivore interactions. Trends Plant Sci 21, 125-133.

18. Jacobsen, D.J. and Raguso, R.A. (2018) Lingering effects of herbivory and plant defenses on pollinators. Curr Biol 28, R1164-R1169.

19. Strauss, S.Y. et al. (1996) Foliar herbivory affects floral characters and plant attractiveness to pollinators: implications for male and female plant fitness. Am Nat 147, 1098-1107.

20. Hoffmeister, M. et al. (2016) Herbivore-induced changes in flower scent and morphology affect the structure of flower-visitor networks but not plant reproduction. Oikos 125, 12411249.

21. Burkle, L.A. and Runyon, J.B. (2016) Drought and leaf herbivory influence floral volatiles and pollinator attraction. Global Change Biol 22, 1644-1654.

22. Siebenkäs, A. et al. (2015) Phenotypic plasticity to light and nutrient availability alters functional trait ranking across eight perennial grassland species. AoB PLANTS 7, plv029. 
23. Rozendaal, D.M.A. et al. (2006) Plasticity in leaf traits of 38 tropical tree species in response to light; relationships with light demand and adult stature. Funct Ecol 20, 207-216.

24. Schiestl, F.P. et al. (2014) Herbivory and floral signaling: phenotypic plasticity and tradeoffs between reproduction and indirect defense. New Phytol 203, 257-266.

25. Poveda, K. et al. (2005) Floral trait expression and plant fitness in response to below- and aboveground plant-animal interactions. Perspect Plant Ecol Evol Syst 7, 77-83.

26. Thaler, J.S. et al. (2012) Evolution of jasmonate and salicylate signal crosstalk. Trends Plant Sci 17, 260-270.

27. Ali, J.G. and Agrawal, A.A. (2012) Specialist versus generalist insect herbivores and plant defense. Trends Plant Sci 17, 293-302.

28. Johnson, S.N. et al. (2016) Roots under attack: contrasting plant responses to below-and aboveground insect herbivory. New Phytol 210, 413-418.

29. Erb, M. et al. (2012) Role of phytohormones in insect-specific plant reactions. Trends Plant Sci 17, 250-259.

30. Bruinsma, M. et al. (2014) Folivory affects composition of nectar, floral odor and modifies pollinator behavior. J Chem Ecol 40, 39-49.

31. Bruinsma, M. et al. (2008) Differential effects of jasmonic acid treatment of Brassica nigra on the attraction of pollinators, parasitoids, and butterflies. Entomol Exp Appl 128, 109-116.

32. Pieterse, C.M.J. et al. (2012) Hormonal modulation of plant immunity. Annu Rev Cell Dev Biol 28, 489-521.

33. Jensen, A.B. et al. (2002) Fusion genetic analysis of jasmonate-signalling mutants in Arabidopsis. The Plant Journal 29, 595-606.

34. Zhou, Y. et al. (2017) Insects (Thrips hawaiiensis (Morgan)) change the stereochemical configuration of 1-phenylethanol emitted from tea (Camellia sinensis) flowers. RSC Advances 7, 32336-32343. 
35. Peng, Q. et al. (2018) Functional characterization of an allene oxide synthase involved in biosynthesis of jasmonic acid and its influence on metabolite profiles and ethylene formation in tea (Camellia sinensis) flowers. Int J Mol Sci 19, 2440.

36. Chrétien, L.T.S. et al. (2018) Caterpillars induce jasmonates in flowers and alter plant responses to a second attacker. New Phytol 217, 1279-1291.

37. McArt, S.H. et al. (2013) Leaf herbivory increases plant fitness via induced resistance to seed predators. Ecology 94, 966-975.

38. Schmid, M. et al. (2005) A gene expression map of Arabidopsis thaliana development. Nat Genet 37, 501-506.

39. Hause, B. et al. (2000) Tissue-specific oxylipin signature of tomato flowers: allene oxide cyclase is highly expressed in distinct flower organs and vascular bundles. The Plant Journal 24, 113-126.

40. Miersch, O. et al. (2004) Constitutive overexpression of allene oxide cyclase in tomato (Lycopersicon esculentum cv. Lukullus) elevates levels of some jasmonates and octadecanoids in flower organs but not in leaves. Phytochemistry 65, 847-856.

41. Ishiguro, S. et al. (2001) The DEFECTIVE IN ANTHER DEHISCENCE1 gene encodes a novel phospholipase A1 catalyzing the initial step of jasmonic acid biosynthesis, which synchronizes pollen maturation, anther dehiscence, and flower opening in Arabidopsis. The Plant Cell 13, 2191-2209.

42. Rodríguez-Concepción, M. and Beltrán, J.P. (1995) Repression of the pea lipoxygenase gene loxg is associated with carpel development. Plant Mol Biol 27, 887-899.

43. Li, R. et al. (2017) Flower-specific jasmonate signaling regulates constitutive floral defenses in wild tobacco. Proc Nat Acad Sci USA 114, E7205-E7214.

44. Reeves, P.H. et al. (2012) A regulatory network for coordinated flower maturation. PLoS Genet 8, e1002506. 
45. Stitz, M. et al. (2014) Jasmonoyl-L-Isoleucine coordinates metabolic networks required for anthesis and floral attractant emission in wild tobacco (Nicotiana attenuata). The Plant Cell 26, 3964-3983.

46. Sherif, S. et al. (2015) A stable JAZ protein from peach mediates the transition from outcrossing to self-pollination. BMC Biol 13, 11.

47. Oh, Y. et al. (2013) A jasmonate ZIM-domain protein NaJAZd regulates floral jasmonic acid levels and counteracts flower abscission in Nicotiana attenuata plants. PLOS ONE 8, e57868.

48. Zhai, Q. et al. (2015) Transcriptional mechanism of jasmonate receptor COI1-mediated delay of flowering time in Arabidopsis. The Plant Cell 27, 2814-2828.

49. Yu, X. et al. (2018) The jasmonate ZIM-domain protein gene SIJAZ2 regulates plant morphology and accelerates flower initiation in Solanum lycopersicum plants. Plant Sci 267, 65-73.

50. Wang, H. et al. (2017) The bHLH transcription factors MYC2, MYC3, and MYC4 are required for jasmonate-mediated inhibition of flowering in Arabidopsis. Mol Plant 10, 14611464.

51. Bruckhoff, V. et al. (2016) Functional characterization of CYP94-genes and identification of a novel jasmonate catabolite in flowers. PLoS ONE 11, e0159875.

52. Wagstaff, C. et al. (2009) A molecular and structural characterization of senescing Arabidopsis siliques and comparison of transcriptional profiles with senescing petals and leaves. The Plant Journal 57, 690-705.

53. Ederli, L. et al. (2015) Arabidopsis flower specific defense gene expression patterns affect resistance to pathogens. Front Plant Sci 6.

54. Dezar, C.A. et al. (2011) HAHB10, a sunflower HD-Zip II transcription factor, participates in the induction of flowering and in the control of phytohormone-mediated responses to biotic stress. J Exp Bot 62, 1061-1076. 
55. Kessler, A. and Halitschke, R. (2009) Testing the potential for conflicting selection on floral chemical traits by pollinators and herbivores: predictions and case study. Funct Ecol 23, 901-912.

56. Barber, N.A. et al. (2011) Effects of above-and belowground herbivory on growth, pollination, and reproduction in cucumber. Oecologia 165, 377-386.

57. Barton, K.E. and Boege, K. (2017) Future directions in the ontogeny of plant defence: understanding the evolutionary causes and consequences. Ecol Lett 20, 403-411.

58. Diezel, C. et al. (2011) Mechanisms of optimal defense patterns in Nicotiana attenuata: Flowering attenuates herbivory-elicited ethylene and jasmonate signaling. J Integr Plant Biol $53,971-983$.

59. Desurmont, G.A. et al. (2015) Floral volatiles interfere with plant attraction of parasitoids: Ontogeny-dependent infochemical dynamics in Brassica rapa. BMC Ecol 15, 17.

60. Barton, K.E. and Koricheva, J. (2010) The ontogeny of plant defense and herbivory: Characterizing general patterns using meta-analysis. Am Nat 175, 481-493.

61. Dannon, E.A. et al. (2010) Effects of volatiles from Maruca vitrata larvae and caterpillarinfested flowers of their host plant Vigna unguiculata on the foraging behavior of the parasitoid Apanteles taragamae. J Chem Ecol 36, 1083-1091.

62. Silveira, T.A. et al. (2018) Phloem-feeding herbivory on flowering melon plants enhances attraction of parasitoids by shifting floral to defensive volatiles. Arthropod Plant Inte 12, 751760.

63. Schuman, M.C. et al. (2012) Herbivory-induced volatiles function as defenses increasing fitness of the native plant Nicotiana attenuata in nature. Elife 1, e00007.

64. Knauer, A.C. et al. (2018) Crab spiders impact floral-signal evolution indirectly through removal of florivores. Nat Commun 9, 1367.

65. Poveda, K. et al. (2003) Effects of below-and above-ground herbivores on plant growth, flower visitation and seed set. Oecologia 135, 601-605. 
66. Soper Gorden, N.L. and Adler, L.S. (2018) Consequences of multiple flower-insect interactions for subsequent plant-insect interactions and plant reproduction. Am J Bot 105, $1-12$.

67. Cozzolino, S. et al. (2015) Herbivory increases fruit set in Silene latifolia: A consequence of induced pollinator-attracting floral volatiles? J Chem Ecol 41, 622-630.

68. Rusman, Q. et al. (2018) Dealing with mutualists and antagonists: Specificity of plantmediated interactions between herbivores and flower visitors, and consequences for plant fitness. Funct Ecol 32, 1022-1035.

69. Soper Gorden, N.L. and Adler, L.S. (2016) Florivory shapes both leaf and floral interactions. Ecosphere 7, e01326.

70. McCall, A.C. et al. (2018) Leaf herbivory induces resistance against florivores in Raphanus sativus. Botany 96, 337-343.

71. Li, R. et al. (2018) Jasmonate signaling makes flowers attractive to pollinators and repellant to florivores in nature. J Integr Plant Biol 60, 190-194.

72. Poelman, E.H. and Kessler, A. (2016) Keystone herbivores and the evolution of plant defenses. Trends Plant Sci 21, 477-485.

73. Chautá, A. et al. (2017) Leaf herbivory imposes fitness costs mediated by hummingbird and insect pollinators. PLoS ONE 12, e0188408.

74. Ghyselen, C. et al. (2016) Is there a missing link? Effects of root herbivory on plantpollinator interactions and reproductive output in a monocarpic species. Plant Biol 18, 156163.

75. Krupnick, G.A. and Weis, A.E. (1999) The effect of floral herbivory on male and female reproductive success in Isomeris arborea. Ecology 80, 135-149.

76. Wright, G.A. and Schiestl, F.P. (2009) The evolution of floral scent: the influence of olfactory learning by insect pollinators on the honest signalling of floral rewards. Funct Ecol 23, 841-851. 
77. Junker, R.R. et al. (2018) Covariation and phenotypic integration in chemical communication displays: biosynthetic constraints and eco-evolutionary implications. New Phytol 220, 739-749.

78. Johnson, M.T.J. et al. (2015) Evolutionary interactions between plant reproduction and defense against herbivores. Annu Rev Ecol Evol Syst 46, 191-213.

79. Penet, L. et al. (2009) Florivory increases selfing: an experimental study in the wild strawberry, Fragaria virginiana. Plant Biol 11, 38-45.

80. Theis, N. and Adler, L.S. (2012) Advertising to the enemy: enhanced floral fragrance increases beetle attraction and reduces plant reproduction. Ecology 93, 430-435.

81. Erb, M. (2018) Plant defenses against herbivory: Closing the fitness gap. Trends Plant Sci 23, 187-194.

82. Lucas-Barbosa, D. et al. (2014) Caught between parasitoids and predators - Survival of a specialist herbivore on leaves and flowers of mustard plants. J Chem Ecol 40, 621-631.

83. Lucas-Barbosa, D. et al. (2013) Reproductive escape: annual plant responds to butterfly eggs by accelerating seed production. Funct Ecol 27, 245-254.

84. Aleklett, K. et al. (2014) The microbial ecology of flowers: an emerging frontier in phyllosphere research. Botany 92, 253-266.

85. Dötterl, S. and Vereecken, N.J. (2010) The chemical ecology and evolution of bee-flower interactions: a review and perspectives. Can J Zool 88, 668-697.

86. Steets, J.A. et al. (2006) Consequences of vegetative herbivory for maintenance of intermediate outcrossing in an annual plant. Ecology 87, 2717-2727.

87. Stam, J.M. et al. (2018) Order of herbivore arrival on wild cabbage populations influences subsequent arthropod community development. Oikos 127, 1482-1493.

88. Allard, S.M. et al. (2018) Insect exclusion limits variation in bacterial microbiomes of tomato flowers and fruit. J Appl Microbiol 125, 1749-1760. 
89. Aizenberg-Gershtein, Y. et al. (2015) Pyridine-type alkaloid composition affects bacterial community composition of floral nectar. Sci Rep UK 5, 11536.

90. Adler, L.S. et al. (2006) Leaf herbivory and nutrients increase nectar alkaloids. Ecol Lett 9, 960-967.

91. Ashman, T.-L. (2004) 24 - Flower Longevity. In Plant Cell Death Processes (Noodén, L.D. ed), pp. 349-362, Academic Press.

92. Utsumi, S. et al. (2010) Linkages among trait-mediated indirect effects: a new framework for the indirect interaction web. Popul Ecol 52, 485-497.

93. Cardel, Y.J. and Koptur, S. (2010) Effects of florivory on the pollination of flowers: an experimental field study with a perennial plant. Int J Plant Sci 171, 283-292.

94. Muola, A. et al. (2017) Direct and pollinator-mediated effects of herbivory on strawberry and the potential for improved resistance. Front Plant Sci 8.

95. Oguro, M. and Sakai, S. (2009) Floral herbivory at different stages of flower development changes reproduction in Iris gracilipes (Iridaceae). Plant Ecol 202, 221-234.

96. Botto-Mahan, C. et al. (2011) Floral herbivory affects female reproductive success and pollinator visitation in the perennial herb Alstroemeria ligtu (Alstroemeriaceae). Int J Plant Sci 172, 1130-1136.

97. Sõber, V. et al. (2010) Florivores decrease pollinator visitation in a self-incompatible plant. Basic Appl Ecol 11, 669-675.

98. Harder, L.D. and Johnson, S.D. (2005) Adaptive plasticity of floral display size in animalpollinated plants. Proc R Soc B 272, 2651-2657.

99. Junker, R.R. et al. (2011) Composition of epiphytic bacterial communities differs on petals and leaves. Plant Biol 13, 918-924.

100. Adler, L.S. et al. (2012) Reliance on pollinators predicts defensive chemistry across tobacco species. Ecol Lett 15, 1140-1148. 
101. Armbruster, W.S. et al. (2009) Macroevolutionary patterns of defense and pollination in Dalechampia vines: Adaptation, exaptation, and evolutionary novelty. Proc Nat Acad Sci USA $106,18085-18090$.

102. Guimarães Jr, P.R. et al. (2017) Indirect effects drive coevolution in mutualistic networks. Nature 550, 511-514.

103. Siepielski, A.M. and Benkman, C.W. (2004) Interactions among moths, crossbills, squirrels, and lodgepole pine in a geographic selection mosiac. Evolution 58, 95-101.

104. Haloin, J.R. and Strauss, S.Y. (2008) Interplay between ecological communities and evolution. Ann N Y Acad Sci 1133, 87-125.

105. Agrawal, A.A. (2007) Macroevolution of plant defense strategies. Trends Ecol Evol 22, 103-109.

106. Zangerl, A. and Berenbaum, M. (2009) Effects of florivory on floral volatile emissions and pollination success in the wild parsnip. Arthropod Plant Inte 3, 181-191.

107. Ivey, C.T. and Carr, D.E. (2005) Effects of herbivory and inbreeding on the pollinators and mating system of Mimulus guttatus (Phrymaceae). Am J Bot 92, 1641-1649.

108. Irwin, R.E. and Adler, L.S. (2006) Correlations among traits associated with herbivore resistance and pollination: implications for pollination and nectar robbing in a distylous plant. Am J Bot 93, 64-72.

109. Herms, D.A. and Mattson, W.J. (1992) The dilemma of plants: to grow or defend. Q Rev Biol 67, 283-335.

110. Rivas-San Vicente, M. and Plasencia, J. (2011) Salicylic acid beyond defence: its role in plant growth and development. J Exp Bot 62, 3321-3338.

111. Yuan, Z. and Zhang, D. (2015) Roles of jasmonate signalling in plant inflorescence and flower development. Curr Opin Plant Biol 27, 44-51.

112. Avanci, N. et al. (2010) Jasmonates are phytohormones with multiple functions, including plant defense and reproduction. Gen Mol Res 9, 484-505. 
113. Rasmann, S. et al. (2018) Pleiotropic effect of the Flowering Locus C on plant resistance and defence against insect herbivores. J Ecol 106, 1244-1255.

114. van Es, S.W. et al. (2018) Novel functions of the Arabidopsis transcription factor TCP5 in petal development and ethylene biosynthesis. The Plant Journal 94, 867-879.

115. Hemm, M.R. et al. (2003) The Arabidopsis ref2 mutant is defective in the gene encoding CYP83A1 and shows both phenylpropanoid and glucosinolate phenotypes. The Plant Cell 15, 179-194.

116. Kaufmann, K. et al. (2009) Target genes of the MADS transcription factor SEPALLATA3: Integration of developmental and hormonal pathways in the Arabidopsis flower. PLoS Biol 7, e1000090.

117. Nagpal, P. et al. (2005) Auxin response factors ARF6 and ARF8 promote jasmonic acid production and flower maturation. Development 132, 4107-4118.

118. Pajoro, A. et al. (2014) The (r)evolution of gene regulatory networks controlling Arabidopsis plant reproduction: a two-decade history. J Exp Bot 65, 4731-4745.

119. Fineblum, W.L. and Rausher, M.D. (1997) Do floral pigmentation genes also influence resistance to enemies? The W locus in Ipomoea purpurea. Ecology 78, 1646-1654.

120. Muhlemann, J.K. et al. (2014) The monolignol pathway contributes to the biosynthesis of volatile phenylpropenes in flowers. New Phytol 204, 661-670.

121. Adler, L.S. (2000) The ecological significance of toxic nectar. Oikos 91, 409-420.

122. Borghi, M. et al. (2017) The sexual advantage of looking, smelling, and tasting good: The metabolic network that produces signals for pollinators. Trends Plant Sci 22, 338-350.

123. Gronquist, M. et al. (2001) Attractive and defensive functions of the ultraviolet pigments of a flower (Hypericum calycinum). Proc Nat Acad Sci USA 98, 13745-13750.

124. Sanders, P.M. et al. (2000) The Arabidopsis DELAYED DEHISCENCE1 gene encodes an enzyme in the jasmonic acid synthesis pathway. The Plant Cell 12, 1041-1061. 
125. Chini, A. et al. (2016) Redundancy and specificity in jasmonate signalling. Curr Opin Plant Biol 33, 147-156.

126. Inouye, D.W. (1980) The terminology of floral larceny. Ecology 61, 1251-1253.

127. Whitman, D.W. and Agrawal, A.A. (2009) What is phenotypic plasticity and why is it important? In Phenotypic plasticity of insects: Mechanisms and consequences (Whitman, D.W. and Ananthakrishnan, T.N. eds), pp. 1-63, Science Publishers, Inc.

\section{Figure legends}

Figure 1. Illustration of the potential effects of herbivore-induced plant responses on flower traits and consequences for flower-associated organisms. Plant responses to herbivory involve the systemic activation of phytohormonal signalling pathways. Overall patterns illustrate that above- and belowground chewing herbivores induce the jasmonic acid (JA) pathway, whereas sap-feeding herbivores induce the salicylic acid (SA) pathway. Both defence and reproduction are mediated by phytohormones such as JA and SA, but also others. Moreover, defence and reproduction are physiologically linked via various mechanisms. Both defence- and reproduction-related processes affect the expression of flower traits. Flower traits mediate interactions with flower-associated community members such as floral microbes, florivores (including seed predators, and nectar or pollen thieves and robbers), pollinators, and predators and parasitoids. Photograph credits: Dani Lucas-Barbosa, Jitte Groothuis, Erik Poelman, and Quint Rusman.

Figure 2. Schematic representation of herbivore-induced changes in flower traits that mediate interactions with flower-associated organisms. Solid lines indicate direct evidence, while dashed lines are based on indirect evidence. The sign in the circle represents the direction of effect, where $+=$ positive effects, $-=$ negative effects,$+/-=$ both positive and negative effects, on the attraction, abundance, or performance of the insects and microbes. The term florivore here includes seed predators, and nectar and pollen thieves and robbers. Photograph credits: Erik Poelman and Quint Rusman. 
691

692

693

694

695

696

697

698

699

700

701

702

703

704

Figure 3. Theoretical framework of how plant-mediated species interactions form a network of trait-mediated species interactions within flowers $(A)$, the whole plant $(B)$, or both $(C, D)$. (A) A flower feeding herbivore that induces a local plant response (inducer) affects floral microbes (receiver), that in turn may affect the same or different flower traits that are received by a pollinator. (B) A leaf feeding herbivore that induces systemic plant responses (inducer) affects a flower feeding herbivore (receiver), that in turn also induces systemic plant responses and affects the same or different flower traits that are perceived by a pollinator. (C) A leaf feeding herbivore that induces systemic plant responses (inducer) affects a pollinator (receiver), that in turn induces local plant responses and affect the same or different flower traits that are received by a predator. (D) Local or systemic induced changes may affect multiple receivers at the same time and have flower-community wide consequences. Photograph credits: Erik Poelman and Quint Rusman. 
Table 1. Phenotypic plasticity of flowers in response to herbivory with its effects on subsequent flower visitation by other organisms.

\begin{tabular}{|c|c|c|c|c|c|c|c|c|c|c|c|c|c|c|c|c|c|c|c|c|c|c|c|c|c|c|c|c|c|c|c|}
\hline \multirow[b]{2}{*}{ 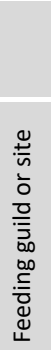 } & \multirow[b]{2}{*}{ 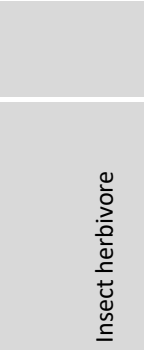 } & \multirow[b]{2}{*}{ 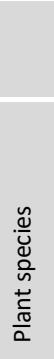 } & \multirow[b]{2}{*}{ 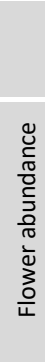 } & \multirow[b]{2}{*}{ 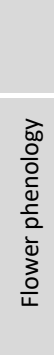 } & \multicolumn{7}{|c|}{ Flower morphology } & \multirow[b]{2}{*}{ 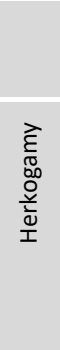 } & \multicolumn{2}{|c|}{$\begin{array}{l}\text { Flower } \\
\text { volatiles }\end{array}$} & \multicolumn{3}{|c|}{ Flower colour } & \multicolumn{2}{|c|}{$\begin{array}{l}\text { Petal } \\
\text { quality }\end{array}$} & \multicolumn{5}{|c|}{ Flower rewards } & \multicolumn{6}{|c|}{ Behavioural responses } & \multirow[b]{2}{*}{$\underset{\mathscr{N}}{\dddot{\Perp}}$} \\
\hline & & & & & 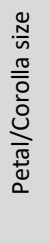 & 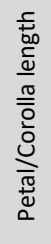 & $\begin{array}{l}\frac{5}{4} \\
\frac{1}{3} \\
\frac{0}{0} \\
\overline{0} \\
\frac{0}{0} \\
\frac{\pi}{0} \\
0 \\
0\end{array}$ & 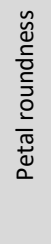 & $\begin{array}{l}\frac{N}{n} \\
\frac{\pi}{\pi} \\
\frac{0}{0} \\
\frac{0}{0} \\
\frac{0}{0} \\
3 \\
\frac{0}{4}\end{array}$ & 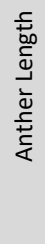 & 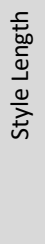 & & 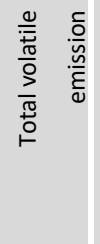 & 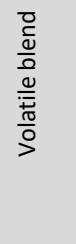 & 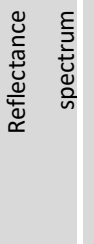 & 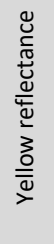 & 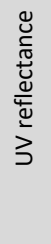 & 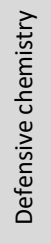 & 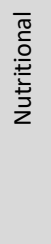 & 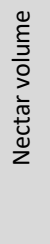 & 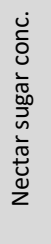 & 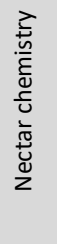 & $\begin{array}{l}\frac{n}{\frac{c}{\pi}} \\
\frac{\overline{0}}{00} \\
\frac{0}{0} \\
\frac{\overline{0}}{0} \\
0\end{array}$ & 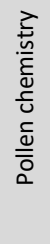 & 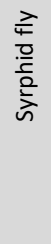 & 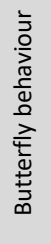 & 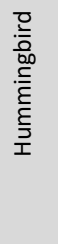 & 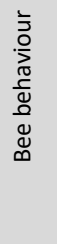 & 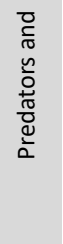 & 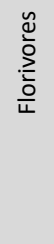 & \\
\hline \multirow{13}{*}{ 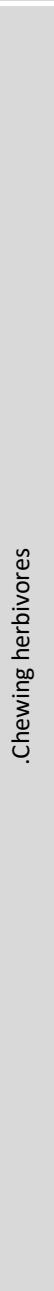 } & $\begin{array}{r}\text { Athalia } \\
\text { rosae }\end{array}$ & $\mathrm{Bn}$ & 0 & . & 0 & - & 0 & - & 0 & . & . & & 0 & c & c & - & 0 & & & - & . & & 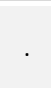 & . & 0 & 0 & & . & . & & [8] \\
\hline & $\begin{array}{l}\text { Depressaria } \\
\text { pastinacella }\end{array}$ & Ps & - & . & . & . & r & r & - & . & . & . & + & c & . & . & . & & . & . & . & & . & . & - & . & & . & . & & [106] \\
\hline & $\begin{array}{r}\text { Manduca } \\
\text { sextra }\end{array}$ & $S p$ & 0 & & . & . & 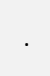 & . & 0 & 0 & - & - & . & c & . & . & . & & & . & . & & . & . & . & . & & - & . & - & [55] \\
\hline & $\begin{array}{c}\text { Phaedon } \\
\text { cochleariae }\end{array}$ & Sa & 0 & $\begin{array}{l}+1 \\
0\end{array}$ & . & . & $\begin{array}{l}+1 \\
0\end{array}$ & . & 0 & . & . & . & $0 / ?$ & $0 / ?$ & . & . & . & . & . & . & . & & . & . & . & . & & . & . & & [20] \\
\hline & $\begin{array}{r}\text { Pieris } \\
\text { brassicae/ }\end{array}$ & $\mathrm{Br}$ & . & + & . & . & . & . & 0 & . & . & . & - & ? & 0 & . & . & 0 & . & . & . & & . & . & . & . & & - & + & & [24] \\
\hline & $\begin{array}{r}\text { Pieris } \\
\text { brassicae }\end{array}$ & $\mathrm{Bn}$ & . & & . & & & & . & . & . & 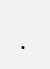 & 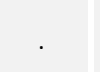 & c & 0 & 0 & 0 & c & & . & . & & & . & - & 0 & & . & . & & [12] \\
\hline & $\begin{array}{r}\text { Pieris } \\
\text { brassicae }\end{array}$ & $\mathrm{Bn}$ & . & . & . & . & . & . & . & . & . & . & . & C & r & . & . & & . & 0 & C & 0 & . & . & - & - & & - & . & & [30] \\
\hline & Pieris rapae & $\mathrm{Rr}$ & 0 & - & . & - & - & . & . & . & . & & . & . & & . & . & & & - & . & & - & . & - & . & & - & . & & [19] \\
\hline & $\begin{array}{r}\text { Plutella } \\
\text { xylostella }\end{array}$ & $\mathrm{Bn}$ & 0 & & 0 & 0 & + & - & + & . & & & 0 & C & C & 0 & 0 & & & . & . & & & . & 0 & - & & . & . & & [8] \\
\hline & $\begin{array}{r}\text { Spodoptera } \\
\text { littoralis }\end{array}$ & $\mathrm{Br}$ & & - & . & . & & . & 0 & . & . & . & - & $?$ & 0 & . & . & + & . & . & . & & . & . & . & . & & - & . & & [24] \\
\hline & $\begin{array}{r}\text { Spodoptera } \\
\text { littoralis }\end{array}$ & Sa & 0 & - & - & & & & & - & & & & & & . & . & & & 0 & . & & & . & . & & & . & . & & [25] \\
\hline & $\begin{array}{r}\text { Spodoptera } \\
\text { littoralis }\end{array}$ & SI & 0 & . & . & 0 & 0 & & . & . & . & & ?/+ & ? & & . & . & & . & 0 & 0 & & & . & . & r & & . & . & & [67] \\
\hline & $\begin{array}{r}\text { Trichoplusia } \\
\text { ni }\end{array}$ & $\mathrm{Cr}$ & 0 & & . & . & & & - & . & . & & 0 & 0 & & . & . & & & . & . & & & . & . &. & & 0 & . & & [21] \\
\hline
\end{tabular}




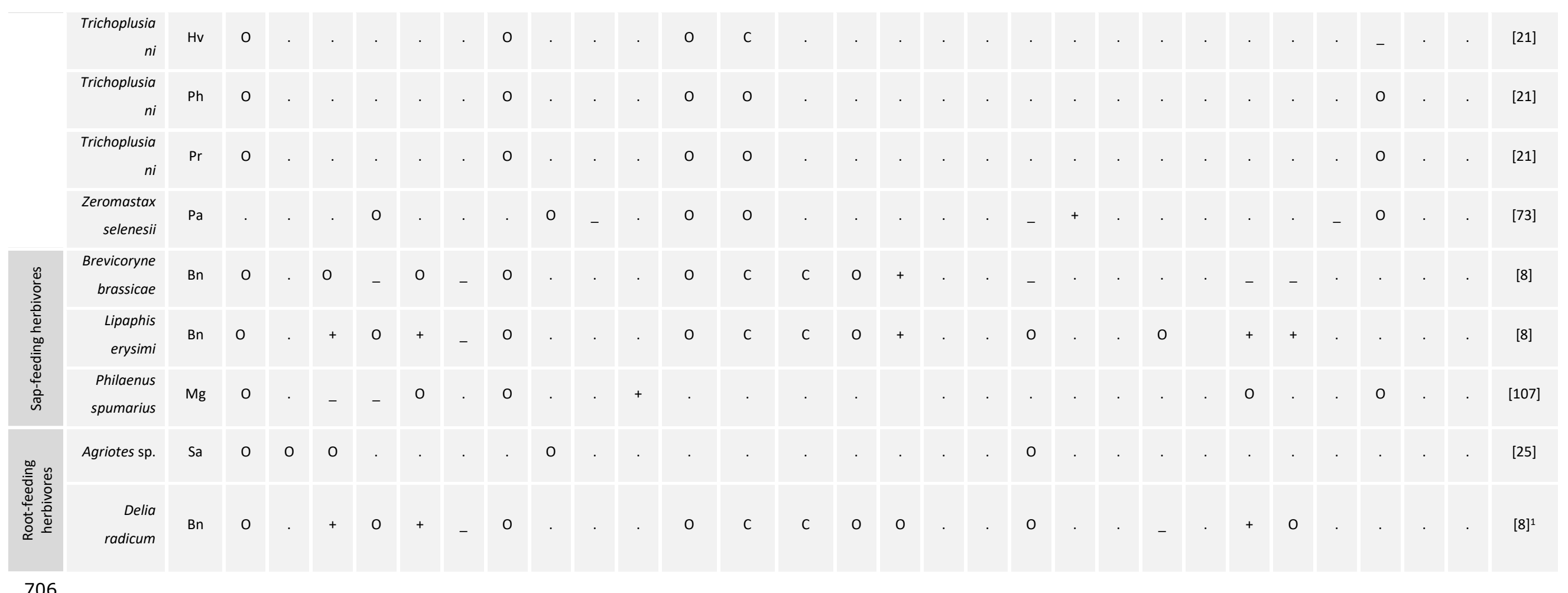

${ }^{1}$ Compared to uninfested plants, herbivory may increase $(+)$, decrease $(-)$, or have neutral $(0)$ effects on plant traits and flower visitors, or herbivory may change traits in a specific direction (C). A dot (.) indicates that the trait/insect response was not assessed for the respective herbivore. Question mark indicates that no exact data was presented or accessible, or no proper statistical analysis was done. We only included studies that assessed 3 or more trait groups. Plant species: $\mathrm{Bn}=$ Brassica nigra,, $\mathrm{Br}=\mathrm{B}$. rapa, $\mathrm{Pa}=$ Palicourea angustifolia, Sa $=$ Sinapis arvensis, $\mathrm{SI}=$ Silene latifolia, $\mathrm{Cr}=$ Campanula rotundifolia, $\mathrm{Hv}=$ Heterotheca villosa, $\mathrm{Ph}=$ Phacelia hastata, $\mathrm{Pr}=$ Potentilla recta, $\mathrm{Mg}=\mathrm{Mimulus}$ guttatus, $\mathrm{Sp}$ = Solanum peruvianum, $\mathrm{Rr}=$ Raphanus raphanistrum, $\mathrm{Ps}=$ Pastinaca sativa. 
Box 1: Physiological links between defence and reproduction

Plant defence and reproduction appear to be linked because defensive and reproductive traits are correlated $[90,108]$ and the expression of flower traits changes in response to herbivore attack. Various mechanisms have been proposed to explain these links $[17,18]$. All traits share resources from the limited nutrient pool of the plant and reallocation of resources to defence can impair reproduction [109]. Defence and reproductive traits share phytohormonal signalling pathways including e.g. jasmonic acid (JA) and salicylic acid (SA) [26, 29, 110-112], and herbivore-induced increases or decreases in any of these phytohormones potentially alter the expression of flower traits [111]. Downstream of phytohormonal signalling, the expression of both flower and defence traits is controlled by genetic and biochemical pathways. Genetic pleiotropy via gene regulatory networks and shared transcription factors, or individual genes involved in multiple regulatory pathways can connect defence and reproduction [113-118]. Biochemical pleiotropy can occur via changes in pools of shared precursors or enzymes [77, $78,119,120]$. Other physiological constraints can lead to co-expression of defence and reproductive traits, such as the passive diffusion of defensive metabolites from the phloem to flower organs $[18,121]$, or herbivory-induced changes in the chemical environment of the cell, which are important for phytohormonal signalling [29], but can also change the redox state of pigments, leading to a shift in light absorbance [122]. Finally, individual traits can have multiple functions and be involved in defence and reproduction [24, 123]. For example, flowering plants use floral volatiles to attract pollinators, but also natural enemies of herbivores [24]. Redirection of flower traits to a defensive function upon herbivore attack with associated changes can render these traits sub-optimal for reproductive functions.

Box 2: Defence regulation in flowers: What can we learn from leaves? Research on flower development suggests that the gene regulatory networks for various phytohormones, and jasmonic acid (JA) in particular, is conserved in leaves and flowers [52, 111]. Flowers show expression of multiple JA biosynthesis genes and products similar as in leaves, such as LIPOXYGENASE (LOX), ALLENE OXIDE SYNTHASE (AOS), 12-oxo-phytodienoic acid (OPDA), and OPDA REDUCTASE (OPR), and produce JA locally [43, 44, 52, 124]. Later steps in JA signalling also seem to work similarly in leaves and flowers, with essential roles for CORONATINE INSENSITIVE 1 (COI1) and JASMONATE ZIM-DOMAIN (JAZ) proteins and WKRY and MYB TFs $[45,48]$. In addition, this is evident from similar expression patterns in leaves 
and flowers for three NAC genes encoding JA regulatory proteins [52] and some JAZ genes: $J A Z 5$ and JAZ7 $[44,125]$. Thus, the backbone of phytohormone signalling, and for JA in particular, appears conserved in leaves and flowers.

\section{Glossary:}

Adaptive: enhancing fitness, i.e. the contribution of an individual to the gene pool of the next generation

Autogamous selfing: Self-pollination within a flower

Folivores: Consumers of aboveground vegetative tissues.

Florivores: Consumers of developing flower buds or mature flowers before the development of the seed coat and including consumers of bracts, sepals, petals, stamens, pistils, pollen and ovules [7]. Also includes sap-feeding consumers that feed from floral stalks.

Nectar thief: flower visitor that collects nectar without damaging flowers, but does not contribute to pollination [126].

Nectar robber: flower visitor that damages flowers while collecting nectar, but does not contribute to pollination [126].

Non-additive selection: Selective effect of a community member depends on the presence of other community members [104].

Pollinator: Flower visitor that contributes to successful pollination, i.e. to the transfer of pollen from one flower to another conspecific flower.

Plant ontogeny: Development of a plant from seed to mature seed-producing plant [57].

Phenotypic plasticity: The capacity of a single genotype to display different phenotypes in response to different environments [127].

Specificity of induction: differential changes in phenotype in response to different inducers. 